\title{
Modeling and control of PMSG based variable speed wind turbine using Proportional Resonant controller
}

\author{
R. Singh ${ }^{1}$, Y. K. Chauhan ${ }^{2}$ \\ Department of Electrical Engineering, School of Engineering \\ Gautam Buddha University, Greater Noida, G. B. Nagar, U.P. \\ ranisingh.jan21@gmail.com, chauhanyk@yahoo.com
}

\begin{abstract}
This paper presents a controlling scheme of a permanent magnet synchronous generator based variable speed wind turbine connected to the utility grid, and a full-scale back-to-back voltage source converter to regulate the voltage at a remote location. The Permanent magnet synchronous generator based wind turbine actively supports the utility grid due to its ability to independently control the active and reactive power at a set value by considering the operating condition and limits. A complete dynamic model of the Permanent magnet synchronous generator based wind turbine together with voltage source converter and a recently introduced controller is presented in this paper. This paper presents the voltage control technique by supervisory reactive power control scheme using Proportional Resonant controller. The basic functional of the proportional resonant controller is to introduce an infinite gain at a selected resonant frequency to eliminate steady-state error at that frequency. By using the Proportional resonant controllers, the converter reference tracking performance can be enhanced which reduces as steady state error controllers can be eliminated.
\end{abstract}

Keywords- Wind energy conversion system (WECS), PMSG, Voltage source converter (VSC), P-R controller.

\section{INTRODUCTION}

The need of renewable energy resources has been increasing rapidly to replace conventional energy resources such as fossil fuel power plants which are limited in quantity. Wind energy is one of the renewable energy resources that is currently growing as an important source of electrical power generation because it has numerous advantages such as, no greenhouse effect, eco-friendly in nature and accessibility [1]. Wind speed fluctuates with respect to time, so the use of variable speed power generation makes the operation of the wind turbine to operate at maximum power coefficient over a wide range variation in wind speeds together with back to back power converter which provides fixed electrical frequency [2]. The kinetic energy of wind is converted into electrical energy by an electric generator connected to the wind turbine. Various types of generators can be used with a wind turbine in WECS that such as wound rotor with slip control, cage rotor and doubly fed induction rotor. Compared with the induction generator, PMSG has the advantage, such as it does not require a system of external excitation, there is no loss of copper in the rotor circuit, low maintenance cost and high power density [3]. The complication associated with a variable speed of the wind energy system is the presence of the gearbox which connect the wind turbine to the generator because of this mechanical element have to suffer from considerable faults and maintenance expenses is also increases so, to improve reliability and reduce maintenance cost gearbox should be eliminated[4]. Use of power converter is very important because it allows the connection of the generator operating at variable speed and the AC power grid at a fixed electrical frequency. The converter rating must be similar to or even larger than the rated power of the generator [5]. Megawatt class wind turbines are specially made for large (offshore) wind farms which are directly connected to a transmission line. The local power flow pattern and the system dynamic characteristics have been changed when such type of wind form are connected to the utility grid because of variation in wind power generation influence the overall power system operation such as power quality, security, stability, and voltage control [6]-[9].

For a three-phase system, synchronous reference frame PI controller together with the voltage forward feed can be used, but usually it requires multiple frame transformation and may be difficult to implement at low-cost. Overcoming the computational burden and still achieving virtually similar frequency response characteristics, a synchronous frame PI controller, develops the Proportional plus resonant (PR) controller for reference tracking in the stationary frame. The recently introduced Proportional-Resonant (PR) controllers and their suitability for voltage control 
of grid-connected converter are described in this paper [10]-[11]. By using Proportional-Resonant controllers, reference tracking performance of the converter can be improved and earlier known shortcoming including steady-state errors in singlephase system and the need of synchronous $d-q$ transformation in three-phase system associated with conventional PI controllers can be eliminated [12]. In short, the basic function of PR controller is to establish an infinite gain at a preferred resonant frequency for reducing steady-state errors at that frequency, which is theoretically similar to PI controller.

The interface between wind farms (WFs), utility grid and controller used are an essential research topic that needs more attention for the optimization of a power system. This paper presents detail designing of the modeling and controlling of a PMSG-based variable speed wind turbine, as well as an optimal controller, are proposed to regulate the voltage by supervisory reactive power control scheme using a proportional resonant controller as shown in Fig. 1.

\section{METHODOLOGY \\ A. Dynamic model of PMSG based wind turbine}

The system described in this paper is shown in Fig.1. The wind energy conversion system consists of a wind farm which contains a group wind turbine interconnected with each other. Each wind farm is equipped with a step-up transformer to increase voltage at the primary level. Then wind farm is connected to the utility grid using a submarine cable and an overhead transmission line to supply active power and reactive power to the local load connected at a point of common coupling. The additional active power requirement of a local load is fulfilled by the utility grid which is connected to the wind form.

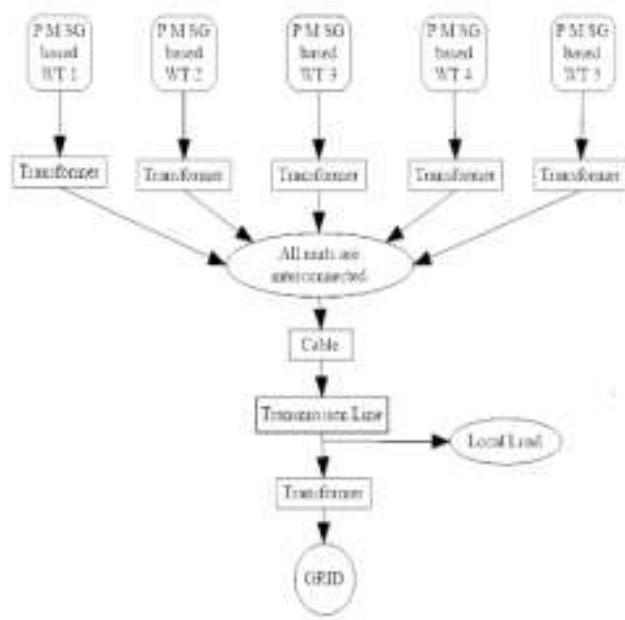

Fig. 1- Grid connected wind turbine system
The whole system has several components such as a wind turbine mechanically coupled with permanent magnet synchronous generator, generator side converter and grid side converter controller, a proportional resonant controller to control the converter, a dc-link capacitor, a grid filter and load, shown in Fig. 2.

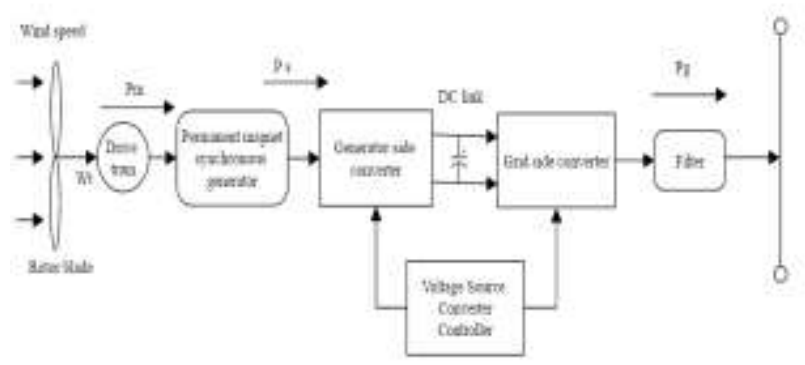

Fig. 2- Permanent magnet synchronous generator wind turbine.

In three phase systems, a conventional controller can be used to control voltage source converter, but it usually requires multiple frame transformation, and have a steady-state error in the stationary reference frame. The complex control of positive and negative sequence component is required under unbalance voltage condition, due to which computation become complex. The disadvantage associated with the modified conventional controllers is the possibility of distorting the line current caused by background harmonics introduced along the feed forward path if the grid voltage is distorted[13]-[15].

Overcoming the computational burden and achieving virtually similar frequency response characteristics as a synchronous frame PI controller develops, the Proportional-Resonant (PR) controller is used. The most important advantage of using PR current controllers is that the voltage can be controlled directly in the stationary reference frame. Therefore, the complication associated with the positive and negative sequence component of the currents is eliminated [16].

PR controller operates at a resonant frequency, at which magnitude is infinite, thus helps in enforcing the steady-state error at zero value. The magnitude of the PR controller rises with the value of $K p$. A smaller value $K i$ gives a lower resonant peak, while a larger value $K i$ gives a higher resonant peak.

\section{B. Model of the wind turbine}

Wind Turbine converts the kinetic energy of wind into mechanical energy. The Variable speed wind turbine is efficient in a wide range of wind speed as compared to a fixed speed wind turbine. VSWT system can capture 5\% larger wind energy 
then FSWT and control of active and reactive power become easier.

Power generated by the wind can be expressed by equ. (1-3).

$P_{m}=0.5 \pi \rho C_{P}(\lambda, \beta) R_{w}{ }^{2} V_{w}{ }^{3}$

$$
C_{P}=0.22\left(\frac{116}{\gamma_{i}}-0.4 \beta-5\right) e^{-12.5 / \gamma_{i}}
$$

$$
\frac{1}{\gamma_{i}}=\frac{1}{\gamma+0.08 \beta^{2}}-\frac{0.035}{1+\beta^{3}}
$$

Where $V_{W}$ is the velocity of wind, $\rho$ is the density of the air, $A$ is the surface area of blade ( $A=\pi R_{W}^{2}$ ), $R_{W}$ is the radius of blade, $\Omega_{W}$ is the rotational velocity of the wind turbine, $C_{P}$ is the coefficient of wind power, $\gamma$ is tip velocity ratio ( $\left.\gamma=\Omega_{W} R_{W} / V_{W}\right)$ and pitch angle $\beta$. When the wind turbine is operated at the rated wind velocity, pitch angle $\beta$ is to be set at an optimal value that allowed the wind turbine to extract maximum energy from the incident wind.

\section{Model of PMSG}

The Permanent magnet synchronous generator is presented by following equ. (4-6):

$$
\begin{aligned}
& \frac{1}{\omega_{b}} \frac{d \psi_{d s}}{d t}=v_{d 1}+R_{s} i_{d s}+\omega_{e} \psi_{q s} \\
& \frac{1}{\omega_{b}} \frac{d \psi_{q s}}{d t}=v_{q 1}+R_{s} i_{q s}-\omega_{e} \psi_{d s}
\end{aligned}
$$

$$
\psi_{d s}=-L_{d s} i_{d s}-\psi_{m}, \quad \psi_{q s}=-L_{q s} i_{q s}
$$

(6)

Where $v$ is voltage, $R$ is resistance, $i$ is current, $\omega_{e}$ is the electrical angular speed of the stator, $\omega_{b}$ is base angular speed in $\mathrm{rad} / \mathrm{s}, L_{s}$ is stator leakage inductance, $\psi_{m}$ is the PMSG exciter flux, and $\psi$ is flux linkage in PMSG. The subscripts $d$ and $q$ indicates the direct axis and quadrature axis components, respectively. The subscript $s$ indicates stator quantity. $T_{e}$ is the electromagnetic torque and $\mathrm{L}$ is inductance. The electrical active and reactive power delivered by the stator side is given by equ. (7).
$P_{s}=v_{d 1} i_{d s}+v_{q 1} i_{q s}$,

$Q_{s}=v_{d 1} i_{q s}-v_{q 1} i_{d}$

\section{Transmission line}

The transmission line is presented by following equ. (8-13).

$\frac{L_{T L}}{\omega_{b}} \frac{d i_{d 1}}{d t}=v_{d 4}-v_{d 3}-R_{T L} i_{d 1}+\omega_{e} L_{T L} i_{q 1}$

(8)

$\frac{L_{T L}}{\omega_{b}} \frac{d i_{q 1}}{d t}=v_{q 4}-v_{q 3}-R_{T L} i_{q 1}-\omega_{e} L_{T L} i_{d 1}$

(9)

$\frac{C_{T L}}{\omega_{b}} \frac{d v_{d 3}}{d t}=i_{d c}^{s}+\omega_{e} C_{T L} v_{q 1}$

(10)

$\frac{C_{T L}}{\omega_{b}} \frac{d v_{q 3}}{d t}=i_{q c}^{s}-\omega_{e} C_{T L} v_{d 3}$

(11)

$\frac{C_{T L}}{\omega_{b}} \frac{d v_{d 4}}{d t}=i_{d c}^{s}+\omega_{e} C_{T L} v_{q 4}$

(12)

$\frac{C_{T L}}{\omega_{b}} \frac{d v_{q 4}}{d t}=i_{q c}^{s}-\omega_{e} C_{T L} v_{d 4}$

(13)

E. Transformer

The transformer is presented by following equ. (1417).

$\frac{L_{t r}}{\omega_{b}} \frac{d i_{d 1}}{d t}=v_{d 2}-v_{d 1}-R_{t r} i_{d 1}+\omega_{e} L_{t r} i_{q 1}$

$\frac{L_{t r}}{\omega_{b}} \frac{d i_{q 1}}{d t}=v_{q 2}-v_{q 1}-R_{t r} i_{q 1}-\omega_{e} L_{t r} i_{d 1}$

$\frac{C_{o}}{\omega_{b}} \frac{d v_{d 1}}{d t}=i_{d 1}+\omega_{e} C_{o} v_{q 1}$

(16)

$\frac{C_{o}}{\omega_{b}} \frac{d v_{q 1}}{d t}=i_{q 1}-\omega_{e} C_{o} v_{d 1}$

(17)

F. Cable

The cable is presented by following equ. (18-21).

$$
\begin{aligned}
& \frac{L_{c a}}{\omega_{b}} \frac{d i_{d 1}}{d t}=v_{d 3}-v_{d 2}-R_{c a} i_{d 1}+\omega_{e} L_{c a} i_{q 1} \\
& \frac{L_{c a}}{\omega_{b}} \frac{d i_{q 1}}{d t}=v_{q 3}-v_{q 2}-R_{c a} i_{q 1}-\omega_{e} L_{c a} i_{d 1} \\
& \frac{C_{c a}}{\omega_{b}} \frac{d v_{d 2}}{d t}=i_{d c}^{s}+\omega_{e} C_{c a} v_{q 2}
\end{aligned}
$$


$\frac{C_{c a}}{\omega_{b}} \frac{d v_{q 2}}{d t}=i_{q c}^{s}-\omega_{e} C_{c a} v_{d 2}$

\section{G. RL Load}

The load is presented by following equ. (22-25).

$$
\begin{aligned}
& \frac{L_{\text {load }}}{\omega_{b}} \frac{d i_{q L}}{d t}=v_{q 4}-R_{\text {load }} i_{q L}-\omega_{e} L_{\text {load }} i_{d L} \\
& \frac{L_{\text {load }}}{\omega_{b}} \frac{d i_{d L}}{d t}=v_{d 4}-R_{\text {load }} i_{d L}+\omega_{e} L_{\text {load }} i_{q L} \\
& \frac{C_{o}}{\omega_{b}} \frac{d v_{d 4}}{d t}=i_{d L}+\omega_{e} C_{o} v_{q 4} \\
& \frac{C_{o}}{\omega_{b}} \frac{d v_{q 4}}{d t}=i_{q L}-\omega_{e} C_{o} v_{d 4}
\end{aligned}
$$

(25)

H. Filter on the grid-side converter

The filter on the grid-side converter is presented by following equations-(26-27).

$$
\begin{aligned}
& \frac{L_{f i l t}}{\omega_{b}} \frac{d i_{d g}}{d t}=v_{d 1}-R_{f i l t} i_{d g}+\omega_{e} L_{f i l t} i_{q g} \\
& \frac{L_{f i l t}}{\omega_{b}} \frac{d i_{q g}}{d t}=v_{q 1}-R_{f i l t} i_{q g}-\omega_{e} L_{f i l t} i_{d g}
\end{aligned}
$$

\section{VOLTAGE SOURCE CONVERTER CONTROLLER}

The voltage source converter control module consists of the generator side converter, the dc link, and the grid side converter controller together with respective input and output variables as shown in Fig. 3. Where, $P_{g}^{s e t}$ is a set-value for active power of the wind turbine terminal determined from the rotational speed of the generator. Since variablespeed wind turbines are usually operated in the power factor control mode to achieve the unity power factor at the terminal of the wind turbine, the reactive power set-points $Q_{S}^{\text {set }}$ is set to zero. The Proportional-Resonant controllers, are introduced for controlling current/voltage of a grid-connected converter which utilize proportional-integral controllers

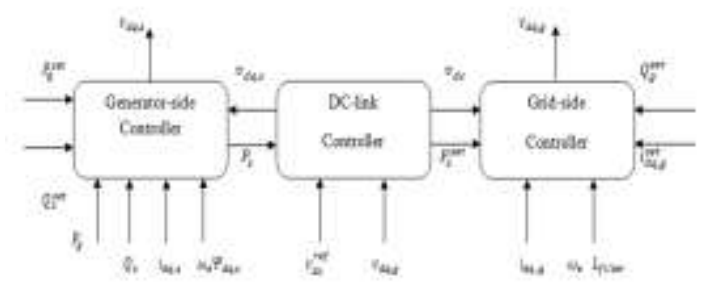

Fig. 3 Block diagram of voltage source controller
Modeling of Generator side controller-The transfer function from the stator voltage to the stator current is presented by equ. (28-29).

$$
\left\lfloor\frac{I_{d s}(s)}{V_{d s}^{\prime}(s)} \frac{I_{q s}(s)}{V_{q s}^{\prime}(s)}\right\rfloor^{T}=\left\lfloor\frac{1}{R_{s}+s\left(L_{d s} / \omega_{b}\right)} \frac{1}{R_{s}+s\left(L_{q s} / \omega_{b}\right)}\right\rceil^{T}
$$

$$
\left\lceil\frac{P_{s}(s)}{I_{d s}(s)} \frac{Q_{g}(s)}{I_{q s}(s)}\right\rfloor^{T}=\left\lfloor R_{s}+s \frac{L_{d s}}{\omega_{b}} R_{s}+s \frac{L_{q s}}{\omega_{b}}\right\rceil^{T}
$$

Modeling of Grid side controller-

The voltage equation for the grid-side converter RL-filter can be expressed by following equ. (30-

31).

$$
\left(\frac{L_{f i l t}}{\omega_{b}}\right) \frac{d i_{d g}}{d t}=v_{d 1}-R_{f i l t} i_{d g}+\omega_{e} L_{f i t t} i_{q g}
$$

$\left(\frac{L_{\text {filt }}}{\omega_{b}}\right) \frac{d i_{q g}}{d t}=v_{q 1}-R_{f i l t} i_{q g}-\omega_{e} L_{f i t t} i_{d g}$

(31)

The transfer function of the filter voltage to current is given by equa. (32).

$$
\left\lfloor\frac{I_{d g}(s)}{V_{d 1}(s)} \frac{I_{q g}(s)}{V_{q 1}(s)}\right]^{T}=\left\lfloor\frac{1}{R_{\text {filt }}+s\left(L_{\text {filt }} / \omega_{b}\right)} \frac{1}{R_{\text {filt }}+s\left(L_{\text {fith }} / \omega_{b}\right)}\right\rfloor^{T}
$$

The inputs applied to the grid-side controller are the set values for the currents, which flows to the grid through the VSC. The set-values of the input currents are calculated by the active and reactive power commands $P_{s}^{\text {set }}$ and $Q_{g}^{\text {set }}$ is presented by equ. (33):

$\left[\begin{array}{c}i_{q g}^{s e t} \\ i_{d g}^{s e t}\end{array}\right]=\left[\begin{array}{cc}v_{q 1} & v_{d 1} \\ -v_{d 1} & v_{q 1}\end{array}\right]^{-1}\left[\begin{array}{l}P_{s}^{s e t} \\ Q_{g}^{s e t}\end{array}\right]$

(33)

where $P_{s}^{\text {set }}$ and $Q_{g}^{\text {set }}$ are the set-point of the active and reactive power commands. The value of $P_{S}^{\text {set }}$ is provided by the dc-link controller, which determines the flow of active power and regulates the dc-link voltage by driving it to a constant reference value.

DC-link dynamic model and its controller-

The capacitor used in the dc-link is an energy storage device. The power transferred by the stator circuit of the PMSG is expressed by equ. (34).

$$
\frac{1}{2} \frac{C_{d c}}{\omega_{b}} \frac{d v_{d c}^{2}}{d t}=P_{g}-P_{s}
$$




\section{THE SUPERVISORY REACTIVE POWER CONTROL}

The purpose of the supervisory reactive power control is to regulate the voltage at the specified remote point of common coupling by adjusting the reactive power produced by the grid-side converter, by taking into account its operating state and limits. The control objective is to utilize Qj from the gridside VSC to control the voltage at the PCC to the predefined value by the reactive power set-point control signal Qset $\mathrm{j}$. When controlling WT, it is important that the operating limit of WT is not exceeded. The reactive power required from an individual grid-side converter of the VSC can be computed by equ. (35).

$$
Q_{j}^{\text {set }}=\min \left\{Q_{j}^{\max }, \frac{Q_{j}^{\max }}{Q_{1}^{\max }+\ldots+Q_{5}^{\max }} \Delta Q_{p c c}\right\}
$$

where $\mathrm{j}=1, \ldots, 5, Q_{j}^{\max }$ is the maximum reactive power (limit) that the $\mathrm{jth}$ grid-side converter can provide, and $\Delta \mathrm{Qpcc}$ is the total reactive power required to support the voltage at the PCC.

Thus, the maximum available reactive power from the each grid side converter can be expressed by equ.(36)

$Q_{j}^{\max }=\sqrt{\left(S_{j}^{\max }\right)^{2}-P_{j}^{2}}$

(36)

By using Proportional-Resonance controllers, reference tracking performance of the converter can be improved and drawbacks associated with the conventional controllers are eliminated. The shortcoming contains steady-state error in a singlephase systems and the need of synchronous $d-q$ transformation in a three-phase systems. On the same control scheme as in PR controller, the PR filters can also be used for generating a harmonic command reference mainly in an active power filter, especially for the single-phase systems, where $\mathrm{d}-\mathrm{q}$ transformation theory is not directly applicable shown by equ. (37). One more advantage related with the PR controllers and filters is the possibility of implementing selective harmonic compensation without requiring excessive computational resources.

$$
\mathrm{G}(\mathrm{s})=\mathrm{K}_{\mathrm{P}}+K_{i} \frac{s}{s^{2}+\omega^{2}}
$$

Where $\mathrm{Kp}$ is Proportional coefficient, $\mathrm{Ki}$ is Integrator coefficient and $\omega$ is resonant frequency.

The whole system contains a reactive power control method for a grid tied single phase Voltage source inverter, which is mainly used for wind power generation system. The main aim is to design a low complex grid synchronization method, which separates the active and reactive power component so that both components can be controlled independently. The AC current and DC voltage controllers used for the VSI are explained.

Controller block diagram as shown in Fig. 4 comprises of a sinusoidal pulse width modulation (SPWM) which is based current controller using a proportional resonant (PR) compensator. The voltage controller that applies a notch filter in the voltage feedback, which helps to reduces the size of the DC-link capacitor.

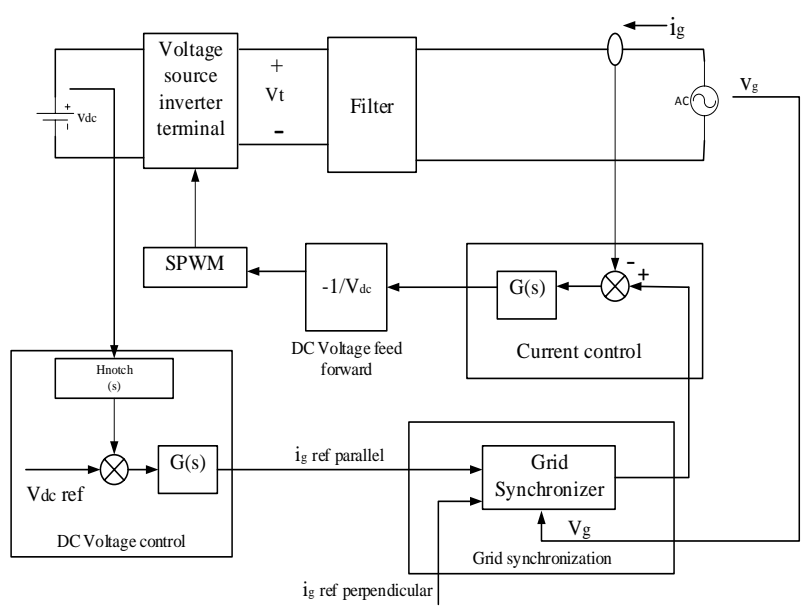

Fig. 4 PR controller block diagram

Current controller regulates the AC current injected into the grid and a voltage controller regulates the DC voltage at a desirable level as shown in Fig. 5. A nonlinear DC voltage feed-forward signal is employed at the output of the current controller so that the modulation signal sent to the SPWM modulator cancels out the effect of the double line frequency ripple that appears on the DC-link. Unlike controlling a three phase VSI, the active and the reactive power of the single phase VSI cannot be controlled by varying id and iq in the $\mathrm{d}-\mathrm{q}$ frame. Instead, a low complexity grid synchronization method is proposed to create a grid current reference that consists of both active and reactive components.

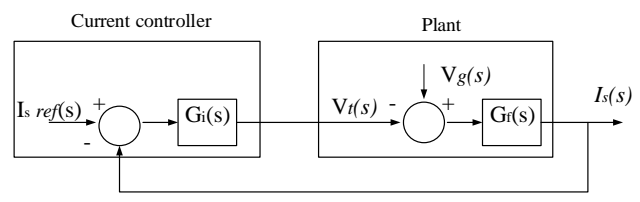

Fig. 5 Current controller block diagram

PR compensator $G_{i}(s)$, used in this work, has a transfer function shown by equ. (38). 


$$
G_{i}(s)=K_{p}^{c}+\frac{K_{i}^{c} s}{s^{2}+2 \zeta \omega_{o} s+\omega_{o}^{2}}
$$

A notch filter is placed on the DC voltage feedback signal to attenuate the ripple shown by equ. (39).

$$
H_{n o t c h}(s)=\frac{s^{2}+2 \zeta_{1} \omega_{n} s+\omega_{n}^{2}}{s^{2}+2 \zeta_{2} \omega_{n} s+\omega_{n}^{2}}
$$

Here $K_{p}^{c}$ and $K_{i}^{c}$ are the proportional and integral gain, $\zeta$ is the damping term and $\omega_{o}$ is the fundamental frequency of the grid voltage.

\section{CASE STUDY AND SIMULATION RESULTS}

Case-1 Local load variation

For this case study PR controller is used in conventional WECS, in which the local load impedance is decreased by $20 \%$ at wind speed of $12 \mathrm{~m} / \mathrm{s}$. The variation in voltage observed at PCC at $20 \%$ decrease in impedance is shown in Fig. 6. The measured value of active and reactive power from the wind farm to the PCC is shown in Fig. 7and Fig. 8 respectively.

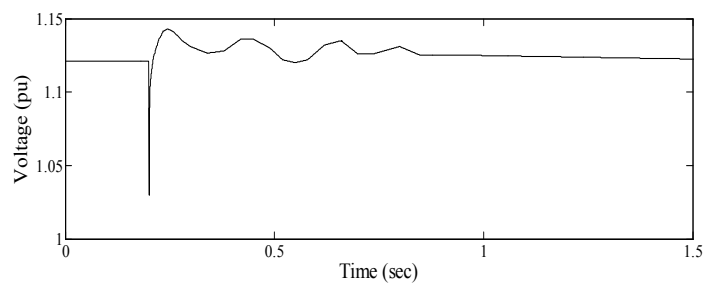

Fig. 6 Voltage at PCC due to load variation using PR controller

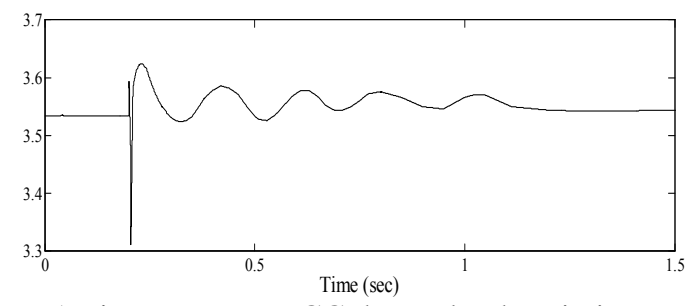

Fig. 7 Active power at PCC due to load variation using PR controller

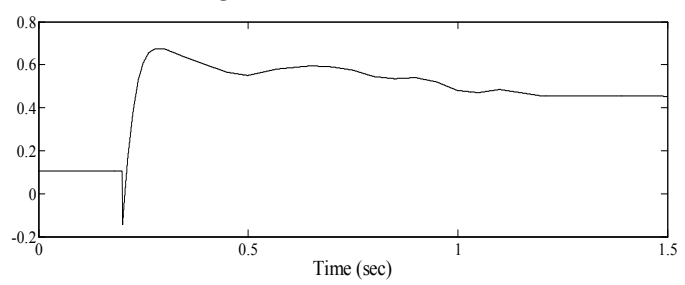

Fig. 8 Reactive load at PCC due to load variation using PR controller

Case-2 Voltage sag in the infinite bus
For this case study PR controller is used in WECS, in which fault is introduce at time $t=0.5 \mathrm{sec}$ in the network which cause $10 \%$ of voltage drop at the bus at wind speed $12 \mathrm{~m} / \mathrm{s}$ as shown in Fig. 9. The measured value of active and reactive power of the wind form at the PCC is shown in Fig. 10 and Fig. 11 respectively.

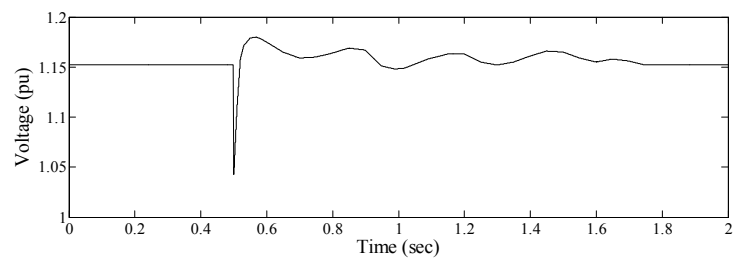

Fig. 9 Voltage at PCC due to voltage sag using PR controller

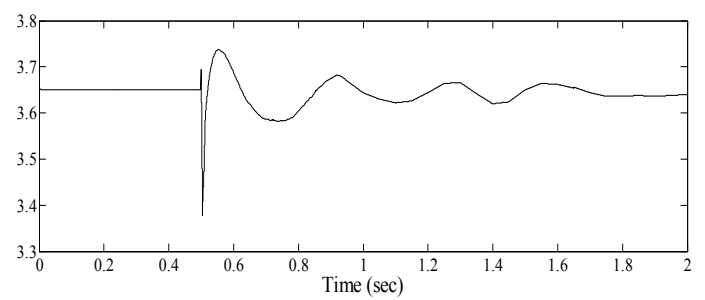

Fig. 10 Active power at PCC due to voltage sag using PR controller

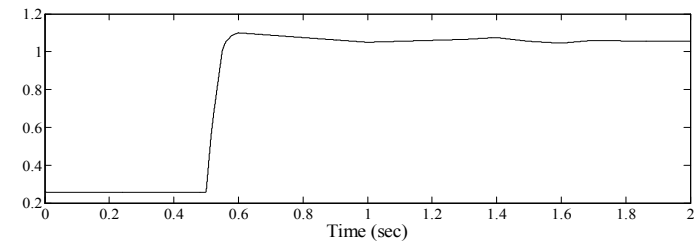

Fig. 11 Reactive power at PCC due to voltage sag using PR controller

Case- 3 Fault ride

For this case study, the fault was assumed in the middle of transmission line at $t=0.2 \mathrm{sec}$ and was subsequently cleared at $0.4 \mathrm{sec}$ by restoring the initial transmission line impedance. Fig. 12 shows the significant voltage swing due to fault in transmission line. Fig. 13 and Fig. 14 shows data of active and reactive power variation of the wind form at PCC due to fault.

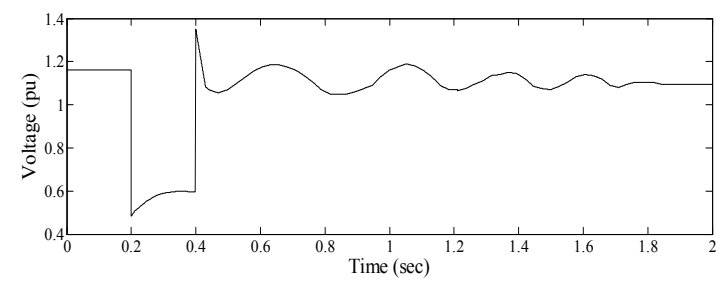

Fig. 12 Voltage at PCC due to fault using PR controller 


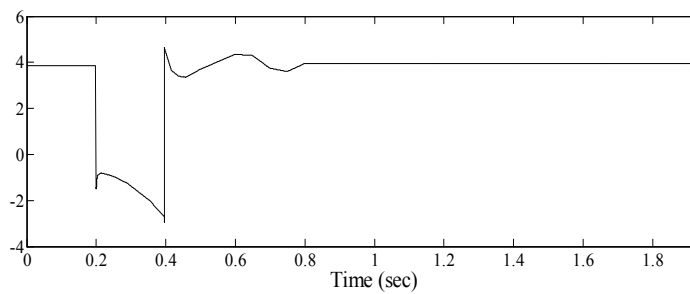

Fig. 13 Active power at PCC due to fault using PR controller

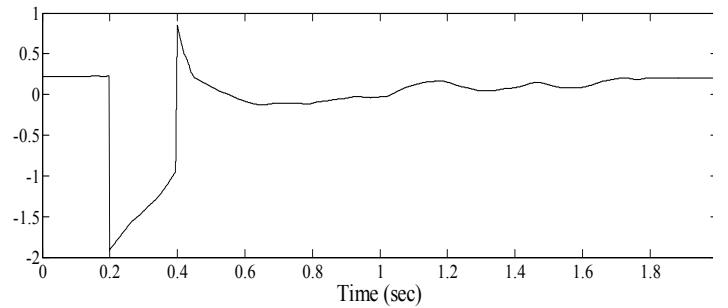

Fig. 14 Reactive power at PCC due to voltage sag using PR controller

\section{CONCLUSION}

In this paper, a method of supervisory reactive power control scheme is used to regulate the voltage at PCC of a permanent magnetic synchronous generator based variable speed wind turbine connected to utility grid. The complete model of the permanent magnet synchronous generator based variable speed wind turbine (VSWT), voltage source converter and controller used is described in detail. The controlling scheme comprises of both the wind turbine control and the power converters control. The active power and reactive power of PMSG based wind turbine is independently controlled by introducing Proportional-Resonant to regulate the voltage at point of common coupling. Steady state error and variation in voltage, active power and reactive power is observed at point of common coupling in various cases such as voltage sag, load variation and fault by P-R controller. By using the Proportional-Resonant controllers in a grid connected WECS, the converter reference tracking performance can be better and steady state error during tracking a sinusoidal signal is reduced in comparison of conventional controller is observed.

\section{APPENDIX}

Table. 1 System Data

\begin{tabular}{|c|c|}
\hline Parameter & Values \\
\hline \multicolumn{2}{|c|}{ Generator Data } \\
\hline Base MVA & $1 \mathrm{MVA}$ \\
\hline Rated voltage & $415 \mathrm{~V}$ \\
\hline Rated frequency & $50 \mathrm{~Hz}$ \\
\hline Stator Resistance & $.0016 \mathrm{ohm}$ \\
\hline Flux linkage & 6.385V.s \\
\hline Inertia & $35 \mathrm{Kg} \cdot \mathrm{m}^{2}$ \\
\hline
\end{tabular}

\begin{tabular}{|l|c|}
\hline DC link capacitor & $1 \mathrm{mF}$ \\
\hline Armature inductance & $.002 \mathrm{H}$ \\
& Network \\
\hline Line inductance & $0.09 \times 10^{-5} \mathrm{H} / \mathrm{km}$ \\
\hline Line resistance & $1.2 \times 10^{-4} \mathrm{ohm} / \mathrm{km}$ \\
\hline Line capacitance & $12.7 \times 10^{-9} \mathrm{~F} / \mathrm{km}$ \\
\hline Frequency & $50 \mathrm{~Hz}$ \\
\hline
\end{tabular}

\section{REFERENCES}

[1] M. Nasiri, J. Milimonfared, and S. H. Fathi, "Modeling analysis and comparison of TSR and OTC methods for MPPT and power smoothing in permanent magnet synchronous generator-based wind turbines," Energy Convers. Manag., vol. 86, pp. 892-900, Oct. 2014.

[2] H. W. Kim, S. S. Kim, and H. S. Ko, "Modeling and control of PMSG based variable speed wind turbine," Electric Power Systems Research., vol. 80, no. 1, pp. 46-52, Jan. 2010.

[3] M. A. Tabrizi, and G. Radman, "Detailed dynamic modeling of Permanent Magnet Synchronous machine based wind turbine for power system dynamic analysis," Proceedings of IEEE Southeastcon, pp. 1-6, 2013.

[4] H. Polinder, F. F. A. vander Pijl, Gert-Jan de Vilder, and Peter J. Tavner, "Comparison of direct drive and geared generator concepts for wind turbines," IEEE Trans. Energy Convers., vol. 21, no. 3, pp. 725-733, Sep. 2006.

[5] M. Rosyadi, Muyeen, Takahashi and J.Tamura, "Transient stability enhancement of variable speed permanent magnet wind generator using adaptive PI-Fuzzy controller," Presented at the PowerTech, 2011 IEEE Trondheim, pp. 1-6, 2011.

[6] R. Doherty, E. Denny and M. O'Malley, "System operation with a significant wind power penetration," IEEE Power Eng. Summer Meeting Proc., pp. 1002-1007, 2004.

[7] K.S. Salman, A.L.J. Teo, "Windmill modeling consideration and factors influencing the stability of a grid-connected wind power-based embedded generator," IEEE Trans. Power Syst., vol.18, pp.793-802, Jan. 2003.

[8] Z. Litipu, K. Nagasaka, "Improve the reliability and environment of power system based on optimal allocation of WPG," IEEE Power Syst. Conf. Exposition Proc., vol. 1, pp. 524-532, 2004.

[9] N. Dizdarevic, M. Majstrovic, S. Zutobradic, "Power quality in a distribution network after wind power plant connection," IEEE Power Syst. Conf. Exposition Proc., vol. 2, pp. 913918, 2004.

[10] D. N. Zmood, D. G. Holme., and G. Bode, "Frequency domain analysis of three-phase linear current regulator," IEEE Trans. Ind. Appl., vol. 37, pp. 601-610, 2001 
[11] D. N. Zmood, and D. G. Holmes, "Stationary frame current regulation of PWM inverters with zero steady-state error," IEEE Trans. Power Electron. ,vol. 18, pp. 814-822, 2003

[12] Kazmierkowski, M., Krishnan, R., and Blaabjerg, F, "Control in power electronics. Selected problems," Academic Press, 2002.

[13] H.S. Ko, "Supervisory voltage control scheme for grid-connected wind farms," $\mathrm{PhD}$ Dissertation, Dept. Elect. and Comp. Eng., Univ. of British Columbia, Vancouver, BC, Canada, 2006.
[14] C.H. Ong, "Dynamic Simulation of Electric Machinery," Prentice Hall, New Jersey, 1998.

[15] J. Morren, S.W.H. de Haan, P. Bauer, J.T.G. Pierik, "Comparison of complete and reduced models of a wind turbine using doubly-fed induction generator," Proceedings of the 10th European Conference on Power Electronics and Applications, 2003.

[16] M. Saeedifard and R. Iravani, "Dynamic Performance of a Modular Multilevel Back-toBack HVDC System," IEEE Transactions on Power Delivery, vol. 25, no. 4, pp. 2903-2912, Oct.

2010. 